\title{
Oral Cancer and Reconstruction: A Case Report
}

Dr. Priyesh Kesharwani ${ }^{1 *}$, Dr. Yash Mathur ${ }^{2}$, Dr. Sonal Kothari ${ }^{3}$, Dr. Pallavi Pawar ${ }^{4}$, Dr. V K Sasank Kuntamukkula ${ }^{5}$, Dr. Nidhi Jayan ${ }^{6}$, Dr. Rahul Vinay Chandra Tiwari ${ }^{7}$

${ }^{1}$ MDS Oral and Maxillofacial Surgeon, Consultant and Private Practitioner DENT-O-FACIAL Multispeciality Clinic, Mira road, Thane-Mumbai, India ${ }^{2}$ MDS OMFS, Fellow Head and Neck OncoSurgeon, Thane, Mumbai, India

${ }^{3}$ MDS PEDODONTICS, Reader, Pacific Dental College n Hospital, Bhelo ka Bedala, Udaipur, Rajasthan, India

${ }^{4}$ Senior Lecturer, Department of Pedodontics n Preventive Dentistry, Pacific Dental College and Hospital, Udaipur, Rajasthan, India

${ }^{5}$ MDS, Assistant Professor, Department of Oral and Maxillofacial Surgery, Sri Sai College of Dental Surgery, Vikarabad, India

${ }^{6}$ PG Student, OMFS, PMS College of Dental Sciences \& Research, Thiruvananthapuram, Kerala, India

${ }^{7}$ FOGS, MDS, Assistant Professor, Department of Oral and Maxillofacial Surgery, Sri Sai College of Dental Surgery, Vikarabad, India

DOI: $10.36348 /$ SJM.2019.v04i09.006

| Received: 03.09.2019 | Accepted: 25.09.2019 | Published: 30.09.2019

*Corresponding author: Dr. Priyesh Kesharwani

\section{Abstract}

The head and neck cancer are sixth most common cancers worldwide with cancer of oral cavity. The basic treatment modality for the carcinoma of oral cavity has been surgery and the large defects resulting from the ablation of the tumors require reconstruction. The PMMC flap offer an easy, less time consuming with minimal postoperative complication as a reconstructive option in the hands of surgeon. In the present case report, 32 years old male patient was diagnosed with squamous cell carcinoma of right buccal mucosa and treatment plan was right segmental mandibulectomy and reconstruction by PMMC. A major pectoralis myocutaneous flap was used to reconstruct a composite oromandibular defect with excellent cosmetic and functional outcome. It provided a suitable and cost-effective reconstruction with low microsurgical risk, relatively short operative time, sufficient soft-tissue replacement and minimum donor site morbidity. Pectoralis major myocutaneous flap was found to be a versatile flap for reconstruction of large defects in Head and Neck region with minimal complication rate.

Keywords: Head and neck cancer, head and neck reconstruction, oral cancer, PMMC flap.

Copyright @ 2019: This is an open-access article distributed under the terms of the Creative Commons Attribution license which permits unrestricted use, distribution, and reproduction in any medium for non-commercial use (NonCommercial, or CC-BY-NC) provided the original author and source are credited.

\section{INTRODUCTION}

Worldwide the head and neck cancer are sixth most common cancers and the cancer of oral cavity is one of the most common. The statistics of the global head and neck cancer indicate that about 640000 cases are reported per year, which results in almost 3, 50,000 deaths per year. The squamous cell carcinoma (SCC) is the most common type of malignancy occurring in the mouth as it accounts for about $90 \%$ of the malignant tumors which occur in the oral cavity $[1,2]$. The carcinomas of oral cavity accounts for around 48000 cases per year and hence are the most common type of head and neck cancer. ${ }^{3}$ Oropharyngeal carcinoma are the third most common in the males and fourth most common in the females in developing countries [3, 4]. The advent of better knowledge and the techniques, the reconstruction in the head and neck region has improved alot. It is a great surgical challenge to perform the reconstruction as the structure, function and esthetics have to be restored [5]. The defects which results from ablation in the maxillofacial region comprised of major reconstructive challenges in order to restore the functions and esthetic aspects because of their complex three dimensional nature [6]. There are various pedicle regional flaps that have been advocated such as PMMC flap, deltopectoral flap, forehead flap [7]. Recently, the free tissue transfer is being practiced in several centers and are therefore considered as first choice for head and neck reconstruction because of the availability of micro vascular surgeon in many centers although, for all the patients, the free flap transfer cannot be used at every institute since it requires special techniques and equipment's for microsurgery [8,9]. Stephen Ariyan in 1979 described about the pectoralis major myocutaneous (PMMC) flap. This flap is most commonly used for the reconstruction in head and neck $[9,10]$. The challenge of reconstruction in large intra oral or extraoral defect is easily accepted by this flap and therefore it is extensively used for maxillofacial reconstruction [11-13]. In order to avoid the bulkiness associated with the flap, the pectoralis major can be used as a muscle flap with or without skin grafting [14].

\section{CASE REPORT}

A 32 years male reported with an ulceroproliferative growth on the right bucco gingival sulcus 
involving the buccal mucosa (Figure-1) measuring approximately $4 * 3 \mathrm{~cm}$ in size. The surface of the swelling was nodular with ragged margins. On palpation, the growth was hard in consistency with blood discharge. The lymph node examination revealed that the lymph nodes were enlarged and hard in consistency. Detailed clinical history and examination of the patients were done. All the relevant investigations were done before the surgical procedure

The plain and contract study of CT neck revealed small or moderate sized ill defined lobulated ulcero-proliferative soft tissue mass lesion from the posterior and superior aspect of the buccal mucosa on the right side directly infiltrating the overlying soft tissue. The lesion was measuring $3.6 * 3.0 * 2.5 \mathrm{cms}$ (ML* $\left.\mathrm{SP}^{*} \mathrm{AP}\right)$ in maximum dimensions and reveal moderate inhomogenous enhancement on post contrast study with extensive areas of central necrotic changes. Multiple enlarged lymph nodes were noted in level I-A, I-B, II and III of the cervical region on the right side, largest measuring $3.5^{*} 2.5 \mathrm{cms}$ in level I-B and of size $1.8^{*} 1.5 \mathrm{cms}$ in level II on the right side with mild to moderate homogenous enhancement on post contrast study and areas of central necrotic changes. No obvious invasion was noted of the other visualized bones or soft tissue in the present scan. The visceral, carotid, post cervical and precervical spaces were normal. Parapharyngeal fat planes were normal and both parotid glands were normal. The treatment was planned as right posterior segmental mandibulectomy and reconstruction with the right pectoralis major myocutaneous flap. Procedure was performed as per standard protocol and as a result patient had a large oromandibular defect in the right facial region due to the loss of soft tissue and mandibular hard tissue (Figure-2). The reconstruction was made with PMMC flap (Figure-3). The outcome of the reconstruction of the composite oromandibular defect with the PMMC flap was functionally as well as cosmetically excellent. It provided a suitable and costeffective reconstruction with relatively short operative time, sufficient soft-tissue replacement, low microsurgical risk and minimum donor site morbidity

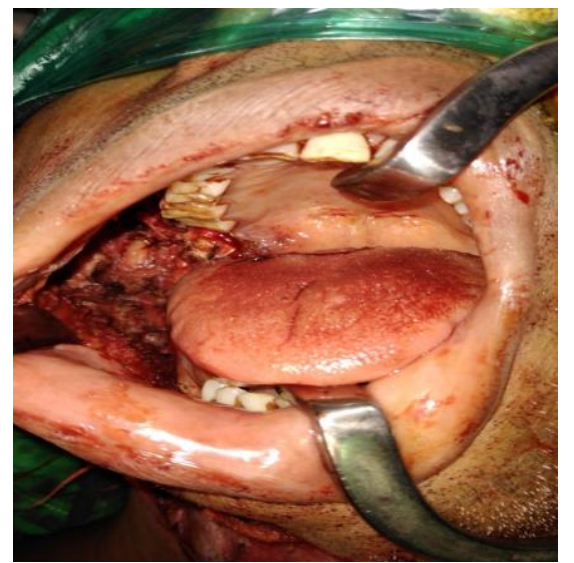

Fig-1: Preoperative intraoral picture showing ulceroproliferative growth on the right buccal mucosa

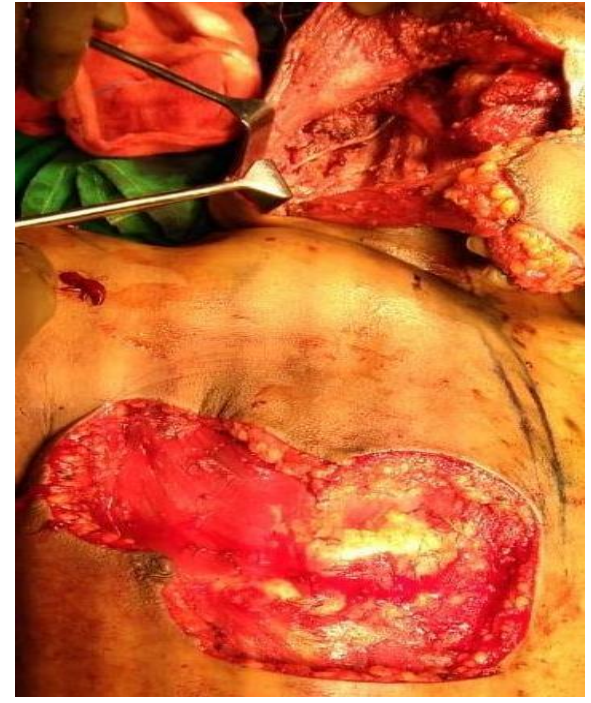

Fig-2: Intraoperative picture showing large oromandibular defect and the PMMC flap site

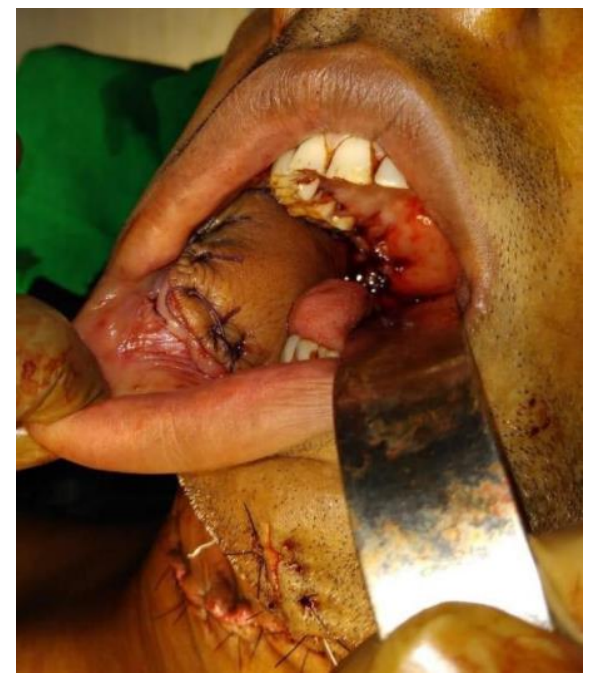

Fig-3: Postoperative picture showing reconstruction and PMMC flap sutured on the right buccal mucosa

\section{DISCUSSION}

A study done by Talabani et al., revealed that the females are less affected than males and it was observed that the highest affected groups were those above 60 years. The peak of total malignancy was seen in the 6th decade of life but in the present case report the mid age group young individual was affected because of increasing use of tobacco in early age.

A study done by Shah JP et al., reported that the flap related complication is 63\%. Another study done by Wilston et al., found 8 failures in 112 flaps four of which were used as extended flaps. A study was done by Ariyan in which he found only 3 cases of partial skin loss $(6.8 \%)$, Deazevedo had a failure rate of $8 \%$ in 55 cases. Infection and orocutaneous fistula was most common complication in many studies which accounts for $23.9 \%$ together [15]. 
In a study done by Kroll et al., a $24.8 \%$ incidence of fistula in 105 patients with intraoral defect was found. Infection was observed in $10 \%$ patients done PMMC flap after head and neck reconstruction in a study done by Mahammad Tahir et al., [10]. Although there is increasing use of microvascular free flap in this era, however, conventional flap like pectoralis major still remains very reliable and versatile myocutaneous flap for primary as well as secondary reconstruction [1, 4]. In head and neck reconstruction, PMMC flap is used extensively due to its proven reliability and multipurpose nature [16]. The main advantage of PMMC flap is that it can be used in a very wide range of defects in the head and neck region including the maxilla, neck as well as tempero-orbital area. The skin paddle can be extended as down as rectus abdominal sheath and the good thing about the PMMC is that a very big skin paddle overlying whole of the muscle can be elevated [17]. In a literature by Kurse et al., it was recommended that PMMC flap is an appropriate flap for the huge defects in the head and neck reconstruction particularly when the large bulky flap is required to cover carotid artery [13]. Like the other myocutaneous flap, PMMC is harvested by single stage reconstructive procedure and does not require any flap delay or release. The morbidity of the donor site is surprisingly low, however, few patients may complain of difficulty in the movement of arm. It is also very useful in the patients with poor clinical conditions as well as for elderly patients. This flap can be used in the cases where there is inadequate recipient vessels for microanastomosis in the neck of the patients who underwent high dose radiotherapy or when there is contraindication to free flap such as medical conditions that make the patients unable to tolerate long surgical procedures or can be used as a salvage procedure after necrosis of free flap. The most common complication when PMMC is used to reconstruct the mucosal defect is the dehiscence of suture which can lead to formation of orocutaneous fistula and salivary leakage and this may lead to the prolongation in hospital stay, wound dehiscence, infection, vascular rapture with marked increase in the morbidity. There is less mentioning of the incidence of recurrence at flap harvesting site however, few cases are reported in the literature. A theoretical disadvantage is the presence of chest hair on the flap used in the man, mostly stage 3 or 4 disease patients need these flaps. The distortion of breast in females is a problem that may be overcome by using a submammary approach, only a muscle flap or by placing the incision laterally. The supraclavicular buldge caused by the muscle as it crosses the clavicle can be unaesthetic.

\section{CONCLUSION}

Reconstruction of composite oromandibular defects of oral malignancy is a challenging problem for oromaxillofacial and plastic surgeons. Pectoralis major myocutaneous flap was found to be a versatile flap for reconstruction of large defects in the head and neck region with minimal complication rate. In today's world of micro vascular flaps, in spite of associated complications, loco regional flaps play a crucial role at oncology centers. PMMC offer a faster, easier and reliable option for reconstruction in post-ablative head and neck surgery.

\section{REFERENCES}

1. Attar, E., Dey, S., Hablas, A., Seifeldin, I. A., Ramadan, M., Rozek, L. S., \& Soliman, A. S. (2010). Head and neck cancer in a developing country: a population-based perspective across 8 years. Oral oncology, 46(8), 591-596.

2. Nevill,e B. W., Damm, D. D., Chi, A. C., \& Allen, C. M. (eds). (2015). Oral and maxillofacial pathology. Elsevier Health Sciences, W. B. Saunders, St. Louis, 356-367.

3. Rahamthullah, U. S., Hussain, S. J., Nasyam, F. A., \& Allareddy, S. (2015). Pectoralis Major Myocutaneous Flap in Oral and Maxillofacial Reconstruction: A case Report. Journal of Research Advanced Dental, 1s2:64-7.

4. Pangam, N., Thorawade, V., Shah, R., Jagade, M., \& Nichalani, S. (2014). Study of Surgical Management and Locoregional Flap Reconstruction in Oral Malighancies. Journal of Dental and Medical Science, 13(5):93-96.

5. Amin, M. M., Naseer, U., Akhtar, A., \& Awan, A. A. (2014). Pectoralis major myocutaneous flap for reconstruction of major neck defects. Journal of Surgery Pakistan (International), 19(2).

6. Rudeš, M., Bilić, M., Jurlina, M., \& Prgomet, D. (2012). Pectoralis major myocutaneous flap in the reconstructive surgery of the head and neck-our experience. Collegium antropologicum, 36(2), 137142.

7. Deo, S. S., Purkayastha, J., Das, D. K., Kar, M., Srinivas, G., Asthana, S., ... \& Shukla, N. K. (2003). Reconstruction of complex oral defects using bi-paddle pectoralis major flap-technical modifications and outcome in 54 cancer patients. Indian Journal of Otolaryngology and Head and Neck Surgery, 55(1), 5-9.

8. Saito, A., Minakawa, H., Saito, N., \& Nagahashi, T. (2012). Indications and outcomes for pedicled pectoralis major myocutaneous flaps at a primary microvascular head and neck reconstructive center. Modern Plastic Surgery, 2(04), 103-107.

9. Vartanian, J. G., Carvalho, A. L., Carvalho, S. M. T., Mizobe, L., Magrin, J., \& Kowalski, L. P. (2004). Pectoralis major and other myofascial/myocutaneous flaps in head and neck cancer reconstruction: experience with 437 cases at a single institution. Head \& neck, 26(12), 10181023.

10. Tahir, M., Ullah, T., \& Khan, A. T. (2011). Clinical Evaluation of pectoralis major myocutaneous flap in head and neck reconstruction. Journal of Postgraduate Medical Institute (Peshawar-Pakistan), 19(1):71-75. 
11. Reddy, V., Vijayakumar, M., Chris Deepak, A., Mahesh, K., \& Jagadish, S. (2013). Pectoralis major myocutaneous (PMMC) flap donor site recurrence in a case of buccal mucosal cancer: a case report. International Journal of Health Science and Research, 3(1):55-57.

12. Lekawale, H., \& Patil, B. (2012). Pectoralis Major Myocutaneous Flap for Oral Cavity Cancer Reconstruction - Our Experience with 30 Cases, 2(3):159-161.

13. Sathyanarayan, G. R., Suresh, K. P., \& Prabhu, V. (2011). Pectoralis Major Myocutaneous (PMMC) Flap for Reconstruction of oro Facial Defect. JIADS, 2(2), 76-8.

14. Belt, P. J., \& Emmett, J. (2004). Local transposition flap repair of the pectoralis major myocutaneous flap donor site. Plastic and reconstructive surgery, 114(3), 732-737.
15. Gupta, A., Agrawal, G., Tiwari, S., Verma, K., Agrawal, R., \& Choudhary, V. (2015). Pectoralis major myocutaneous flap in head and neck reconstruction: an interesting experience from central India regional cancer center. International Journal of Research in Medical Sciences, 3(11), 3065-3068.

16. Leite, A. K. N., Matos, D. L. L., Belli, M., Kulsar, M. A. V., Cernea, C. R., \& Brandao, L. G. (2014). Pectoralis Major Myocutaneous Flap for Head and Neck Reconstruction. Acta Otorhinolaryngologica Italica, 34:389-93.

17. Rahman, Q. B., Karmakar, R., \& Kumar, S. (2012). Thoracoacromial Vessel Based Pectoralis Major Myocutaneous Flap in Oral and Maxillofacial Soft Tissue Defect Reconstruction. Anwer Khan Modern Medical College Journal, 3(2), 23-29. 